\title{
Decellularization and Characterization of Porcine Superflexor Tendon: A Potential Anterior Cruciate Ligament Replacement
}

\author{
Gemma Jones, $\mathrm{PhD}$, Anthony Herbert, $\mathrm{PhD}$, Helen Berry, $\mathrm{PhD}$, Jennifer Helen Edwards, PhD, \\ John Fisher, $\mathrm{PhD}^{2}$, and Eileen Ingham, $\mathrm{PhD}^{1}$
}

The porcine superflexor tendon (SFT) was identified as having appropriate structure and properties for development of a decellularized device for use in anterior cruciate ligament reconstruction. SFTs were decellularized using a combination of freeze-thaw and washes in hypotonic buffer and $0.1 \%(\mathrm{w} / \mathrm{v})$ sodium dodecyl sulfate in hypotonic buffer plus proteinase inhibitors, followed by nuclease treatment and sterilization using peracetic acid. The decellularized biological scaffold was devoid of cells and cell remnants and contained only $13 \mathrm{ng} / \mathrm{mg}$ (dry weight) residual total DNA. Immunohistochemistry showed retention of collagen type I and III and tenascin-C. Quantitative analysis of sulfated sugar and hydroxyproline content revealed a loss of glycosaminoglycans compared with native tissue, but no loss of collagen. The decellularized SFT was biocompatible in vitro and in vivo following implantation in a mouse subcutaneous model for 12 weeks. Uniaxial tensile testing to failure indicated that the gross material properties of decellularized SFTs were not significantly different to native tissue. Decellularized SFTs had an ultimate tensile strength of $61.8 \pm 10.3 \mathrm{MPa}( \pm 95 \%$ confidence limits), a failure strain of $0.29 \pm 0.04$, and a Young's modulus of the collagen phase of $294.1 \pm 61.9 \mathrm{MPa}$. Analysis of the presence of the $\alpha$-Gal (galactose- $\alpha$-1,3-galactose) epitope by immunohistochemistry, lectin binding, and antibody absorption assay indicated that the epitope was reduced, but still present post decellularization. This is discussed in light of the potential role of noncellular $\alpha$-Gal in the acceleration of wound healing and tissue regeneration in the presence of antibodies to $\alpha-G a l$.

Keywords: decellularization, tendon, anterior cruciate ligament

\section{Introduction}

$\mathbf{T}$ HE ANTERIOR CRUCIATE LIGAMENT (ACL) is the main intra-articular ligament in the knee joint ${ }^{1}$ and the most commonly injured, with a reported 50,000-175,000 reconstructions taking place each year in the United States. ${ }^{2}$ Rupture or tearing of the ACL leads to instability of the knee and reduced function, which (if not treated effectively) can lead to degenerative joint disease. ${ }^{3}$ The ACL has limited vascular supply and capacity to heal and therefore if it is ruptured or torn, the only viable treatment is surgical reconstruction. The current gold standard for ACL reconstruction is autologous bone-patellar tendon-bone; however, the use of semitendinosus or gracilis tendon has become more popular in recent years. ${ }^{4,5}$ Autografts offer good results and the advantage of no disease transmission or adverse immune response $^{6,7}$; however, limitations include donor site morbidity, increased operative time, and the potential for the harvested tissue to prove unsuitable. The major alternative is to use tendon allograft with advantages of shorter less complicated surgeries, no donor site morbidity, and the availability of larger grafts. ${ }^{8,9}$ The major disadvantage of ACL reconstruction using allograft is that the donor tissue may suffer an adverse immune response. Reconstruction of the ACL using allograft tissue has also been shown to have a higher failure rate in younger more active patients. ${ }^{6}$

Following ACL reconstruction surgery with autografts or allografts, the endogenous cells are unlikely to survive,

\footnotetext{
${ }^{1}$ Institute of Medical and Biological Engineering, School of Biomedical Sciences, Faculty of Biological Sciences, University of Leeds, Leeds, United Kingdom.

${ }^{2}$ Institute of Medical and Biological Engineering, School of Mechanical Engineering, University of Leeds, Leeds, United Kingdom.

${ }^{3}$ Tissue Regenix Group, The Biocentre Innovation Way, York, United Kingdom.

(C) Gemma Jones, et al., 2017; Published by Mary Ann Liebert, Inc. This Open Access article is distributed under the terms of the Creative Commons Attribution Noncommercial License (http://creativecommons.org/licenses/by-nc/4.0/) which permits any noncommercial use, distribution, and reproduction in any medium, provided the original author(s) and the source are credited.
} 
leading to initial graft deterioration. ${ }^{10}$ During the remodeling process, there is a marked decrease in biomechanical strength of tendon autografts, which can be attributed to initial cell necrosis within the tissue. ${ }^{10}$ Following implantation, the rate of tissue degradation is greater than host cell repopulation. ${ }^{11,12}$ Indeed, it may well be better to use a nonvital graft with a stable matrix, such as an acellular natural tendon scaffold.

Biological scaffolds produced by decellularization of mammalian tissues are used extensively in surgical applications. Mostly derived from porcine small intestinal submucosa, human or animal dermis, or pericardium, their use is typically limited by inadequate biomechanical properties. ${ }^{13}$ The innovation in our approach has been to develop processes for decellularization of the tissue type to be replaced, preserving the physical properties, thus delivering the natural multiscale hierarchical matrix architecture for appropriate tissue-specific biomechanical and biological functions. We have produced tissue-specific acellular biological scaffolds for use in cardiovascular, ${ }^{14}$ musculoskeletal, ${ }^{15,16}$ and wound care ${ }^{17}$ applications. In this study, we describe the decellularization and characterization of porcine superflexor tendon (SFT), which was identified as having appropriate structure and biomechanical properties for potential use in ACL reconstruction.

\section{Materials and Methods}

\section{Tissue procurement}

The hind legs of female, $70 \mathrm{~kg}$, 4-month-old, large White pigs were obtained from an abattoir (J. Penny, Leeds) within $24 \mathrm{~h}$ of slaughter. The SFT is located in the porcine foot running from the toe to the ankle. The SFT was identified after removal of the skin and subcutaneous tissue and cleaned of connective tissue before being aseptically dissected. The porcine SFT divides into two bands approximately halfway along its length and one band was carefully removed, taking care not to damage the remaining tissue. The SFTs were stored at $-80^{\circ} \mathrm{C}$ on filter paper moistened with phosphate-buffered saline (PBS; Oxoid) until required.

\section{Decellularization of porcine SFTs}

SFTs were decellularized in batches of 12. SFTs were subjected to three freeze-thaw cycles at $-80^{\circ} \mathrm{C}$. The first freeze-thaw was conducted on dry tissue. SFTs were then immersed in hypotonic buffer plus proteinase inhibitors (10 mM Tris [Sigma Aldrich]; $2.7 \mathrm{mM}$ disodium ethylenediamine-tetra acetic acid [EDTA; Thermo Fisher Scientific]; $10 \mathrm{KIU} / \mathrm{mL}$ aprotinin [Nordic Pharma], $\mathrm{pH} 8.0$ ), and frozen and thawed at room temperature (RT, 22-25 $\mathrm{C}$ ) twice. SFTs were washed in acetone (WVR International) three times for $1 \mathrm{~h}$ (RT) to remove fat, then washed five times in PBS plus aprotinin $(10 \mathrm{KIU} / \mathrm{mL})$ to remove the acetone at RT. All subsequent steps in the process were conducted on tendons in individual pots containing $100 \mathrm{~mL}$ of solution at $37^{\circ} \mathrm{C}$ with agitation, unless otherwise stated. Tendons were disinfected in a solution of $0.5 \mathrm{mg} / \mathrm{mL}$ gentamicin sulfate (VWR International), $0.05 \mathrm{mg} / \mathrm{mL}$ vancomycin hydrochloride (Sigma), and $0.2 \mathrm{mg} / \mathrm{mL}$ polymyxin B (Sigma) in PBS for $1 \mathrm{~h}$. Tendons were washed in hypotonic buffer for $24 \mathrm{~h}$ and then hypotonic buffer plus $0.1 \%$ (w/v) sodium dodecyl sulfate (SDS; Sigma) for $24 \mathrm{~h}$. The washes in hypotonic buffer and hypotonic buffer plus SDS were repeated twice. SFTs were washed in PBS plus aprotinin three times for $30 \mathrm{~min}, 70 \mathrm{~h}$, and $30 \mathrm{~min}$ before treatment with nuclease $(1 \mathrm{U} / \mathrm{mL}$ benzonase [Merk] in $60 \mathrm{~mL} 50 \mathrm{mM}$ Tris plus $1 \mathrm{mM}$ $\mathrm{MgCl}_{2}$ [Thermo Fisher Scientific] at $\mathrm{pH}$ 7.6) for $2 \mathrm{~h}$, three times. SFTs were washed three times in PBS plus $2.7 \mathrm{mM}$ EDTA before an 18-h wash in hypertonic buffer $(50 \mathrm{mM}$ Tris; $1.5 \mathrm{M} \mathrm{NaCl}$ [Sigma]; pH 7.6). After three 30-min PBS washes, SFTs were sterilized using peracetic acid $(0.1 \% \mathrm{v} / \mathrm{v}$, $\mathrm{pH}$ 6; Sigma) for $3 \mathrm{~h}$. Finally the SFTs were washed in PBS three times for $30 \mathrm{~min}$, twice for $60 \mathrm{~h}$, and once for $120 \mathrm{~h}$ and stored refrigerated in PBS.

\section{Histology and immunohistochemistry}

Six decellularized SFTs were analyzed and compared with native tissue $(n=6)$. Transverse and longitudinal samples were taken from the toe insertion point (toe region), middle, and ankle insertion point (ankle region) of each tendon and fixed in $10 \%(\mathrm{v} / \mathrm{v})$ neutral buffered formalin (NBF; Genta Medical) for histochemical staining and zinc fixative $(0.1 \mathrm{M}$ tris; $3.2 \mathrm{mM}$ calcium acetate [Thermo Fisher scientific], $27 \mathrm{mM}$ zinc acetate [Sigma Aldrich], and $37 \mathrm{mM}$ zinc chloride [Fluka] $\mathrm{pH}$ 7.2) for 4 days for immunohistochemical analysis. The samples were processed automatically (Leica 11020 Tissue processor) and embedded in paraffin wax using standard techniques. For histochemical staining, sections $(6$ and $10 \mu \mathrm{m})$ were taken from the surface through to the central region of each block and stained with hematoxylin (Biostain ready reagent) and eosin (Merck) (H\&E), 4',6-diamidino-2-phenylindole (DAPI; Sigma), Alcian blue (Atom Scientific), and Sirius red (WVR International)/Millers elastin stains (Raymond A Lamb).

For immunohistochemistry, sections were taken at $6 \mu \mathrm{m}$. The Ultra Vision system-HRP kit (Thermo Scientific) was used for antibody detection. Sections were analyzed using monocloncal antibodies to collagen I, collagen II, collagen III (all at 1:50 dilution; Chemicon), and tenascin-C (1:100; Leica Microsystems) and polyclonal antibodies to galactose$\alpha$-1,3-galactose ( $\alpha$-Gal; $0.37 \mathrm{mg} / \mathrm{mL}$; Enzo Life Sciences). Omission of the primary antibody and isotype control antibodies (mouse $\operatorname{IgG1}$; rabbit $\operatorname{IgM}$ ) were used as controls. Sections of native and decellularized SFTs were also treated with $\alpha$-galactosidase for $20-24 \mathrm{~h}$ at $37^{\circ} \mathrm{C}(5 \mathrm{U} / \mathrm{mL}$; Sigma) to remove the $\alpha$-Gal epitope from the tissue as an additional negative control for determination of $\alpha$-Gal. Sections were blocked with dual endogenous enzyme block (Ultra Vision). Antibodies were diluted in Tris-buffered saline (TBS) containing $0.1 \%(\mathrm{w} / \mathrm{v})$ bovine serum albumin (Sigma). The sections were incubated with the diluted antibodies, isotype controls, or antibody diluent only for $1 \mathrm{~h}$, TBS and TBS containing $0.05 \%$ (v/v) Tween (Sigma) were used as wash buffers throughout. The sections were labeled with polymer horseradish peroxidase (HRP), followed by DAB chromagen from the Ultra Vision kit.

The presence of the $\alpha$-Gal epitope in tissue sections was also analyzed using biotinylated GSL-1 lectin (Vector Labs). Sections were blocked with streptavidin/biotin and carbo-free blocking solution (Vector Labs). Lectin was used at $5 \mathrm{mg} / \mathrm{mL}$ in TBS. The streptavidin polymer and IMMpact DAB chromagen (Vector Labs) were used to visualize lectin 
binding. Lectin $(5 \mathrm{mg} / \mathrm{mL})$ absorbed with $200 \mathrm{mM}$ galactose, omission of the lectin, and $\alpha$-galactosidase-treated sections were used as negative controls. All sections were viewed using an Olympus BX51 microscope and imaged using an Olympus XC50 digital camera controlled through Cell B software (Olympus ${ }^{\circledR}$, United Kingdom).

\section{Determination of total DNA content of native and decellularized SFTs}

The total DNA content of six decellularized SFTs was determined and compared with the DNA content of native tissue. Tissue samples were taken from the toe, middle, and ankle regions of each tendon, combined, and macerated using a scalpel blade. The samples were weighed (circa $25 \mathrm{mg}$ fresh tissue and $250 \mathrm{mg}$ decellularized tissue) and freeze-dried to a constant weight. The DNA was extracted using a DNeasy blood and tissue kit (Qiagen) following the manufacturer's instructions. The extracted DNA was then quantified at $260 \mathrm{~nm}$ using a nanodrop spectrophotometer (ND-500 Labtech).

\section{Determination of collagen content of decellularized SFTs}

The total collagen content of native $(n=6)$ and decellularized $(n=6)$ SFTs was determined using the hydroxyproline assay. Samples of native and decellularized tendons were freeze-dried to a constant weight, hydrolyzed in $6 \mathrm{M} \mathrm{HCl}$ for $4 \mathrm{~h}$ at $120^{\circ} \mathrm{C}$, and neutralized with $6 \mathrm{M}$ $\mathrm{NaOH}$. Test samples $(50 \mu \mathrm{L})$ were added to 96 -well plates with $100 \mu \mathrm{L}$ of chloramine-T solution (chloramine-T hydrate; Sigma) for $5 \mathrm{~min}$ with agitation. Ehrlich's reagent (100 $\mu \mathrm{L}$; Sigma) was added to each well and the wells covered and incubated at $60^{\circ} \mathrm{C}$ for $45 \mathrm{~min}$. The absorbance was read at $570 \mathrm{~nm}$. The hydroxyproline content of test samples was determined by interpolation from a standard curve of trans-4-hydroxy-L-proline (Sigma).

\section{Determination of the glycosaminoglycan content of decellularized SFTs}

The glycosaminoglycan (GAG) content of native $(n=6)$ and decellularized $(n=6)$ SFTs was determined using the dimethylene blue assay. Native and decellularized tendon samples were freeze-dried to a constant weight before being digested in papain (1250 units [Sigma] in $25 \mathrm{~mL}$ of $5 \mathrm{mM} \mathrm{L}-$ cysteine hydrochloride plus $5 \mathrm{mM} \mathrm{Na} \mathrm{N}_{2}$ EDTA [WVR International]) for $26 \mathrm{~h}$ at $60^{\circ} \mathrm{C}$ with agitation. Standard or test solutions $(40 \mu \mathrm{L})$ were added to wells of $96-$ well plates with $250 \mu \mathrm{L}$ 1,9-dimethylene blue solution (DMB). Absorbance was read at $525 \mathrm{~nm}$ after 2 min of incubation. The sulfated sugar content of the test samples was determined by interpolation from the standard curve of chondroitin sulfate B $(\mu \mathrm{g} / \mathrm{mL}$; Sigma) versus OD $525 \mathrm{~nm}$.

\section{Semiquantitative analysis of $\alpha$-Gal content of decellularized SFT}

Tissue samples $(100 \mathrm{mg})$ from five different native and decellularized SFTs were macerated and added to individual $1.5-\mathrm{mL}$ microcentrifuge tubes. $\alpha$-Galactosidase $(5 \mathrm{U} / \mathrm{mL}$ in $50 \mathrm{mM}$ Tris $\mathrm{pH}$ 6.0) was added to the samples of native and decellularized tissue and rotated at $37^{\circ} \mathrm{C}$ for $24 \mathrm{~h}$ (negative control tissue). Native, decellularized, and negative control tissues were placed into individual tubes and purified monoclonal antibody to $\alpha$-Gal diluted to $0.37 \mathrm{mg} / \mathrm{mL}$ in TBS was added to all samples. Antibody only (no tissue) was included as a no tissue control. The mixtures were rotated at $4^{\circ} \mathrm{C}$ for $16 \mathrm{~h}$. Following incubation, the samples were centrifuged at $600 \mathrm{~g}$ for $15 \mathrm{~min}$ and the supernatant $(100 \mu \mathrm{L})$ was added to the wells of MaxiSorp plates (Nunc) that had been coated with $50 \mu \mathrm{L} \alpha$-Gal-BSA $(10 \mu \mathrm{g} / \mathrm{mL}$ in PBS; Dextra $)$ overnight at $4^{\circ} \mathrm{C}$ and incubated for $3 \mathrm{~h}$ at RT. Following this, $50 \mu \mathrm{L}$ secondary rabbit anti-mouse HRP antibody (1:1000; Dako) was added to the wells and incubated for $1 \mathrm{~h}$ at RT. The plates were washed with TBS before adding $100 \mu \mathrm{L} o$-phenylenediamine dihydrochloride (OPD) solution (Sigma) and incubating for $10 \mathrm{~min}$ at $\mathrm{RT}$ in the dark. The reaction was stopped with $50 \mu \mathrm{L} 3 \mathrm{M}$ sulfuric acid and the absorbance measured at $490 \mathrm{~nm}$ with a reference filter of $630 \mathrm{~nm}$.

\section{Determination of the biocompatibility of decellularized SFT tissue}

The in vitro biocompatibility of decellularized SFTs $(n=6)$ was determined using contact and extract biocompatibility assays.

Cell culture. Murine 3T3 fibroblastic cells (European Collection of Cell Cultures; ECCAC) were cultured in Dulbecco's modified Eagle's medium (DMEM) plus 10\% (v/v) fetal calf serum (FCS), 2 mM L-glutamine, and $100 \mathrm{U} /$ $\mathrm{mL}$ penicillin/streptomycin (all from Lonza). Baby hamster kidney (BHK; ECCAC) cells were cultured in Glasgow's minimum essential medium plus $5 \%$ (v/v) FCS, $10 \%$ (v/v) tryptose phosphate broth $(29.5 \mathrm{~g} / \mathrm{L}$; Sigma), and $100 \mathrm{U} / \mathrm{mL}$ penicillin/streptomycin. The cells were cultured at $37^{\circ} \mathrm{C}$ in $5 \%(\mathrm{v} / \mathrm{v}) \mathrm{CO}_{2}$ in air in a humidified atmosphere.

Contact biocompatibility assay. Samples from the toe, middle, and ankle regions of decellularized SFTs were attached to the center of wells of a six-well plate (Nunc) using Steri-Strips (3 M; Medisave). Cyanoacrylate (RS Systems) was used as the positive control and Steri-Strip alone as the negative control. BHK and 3T3 cells were seeded at $5 \times 10^{5}$ cells in $2 \mathrm{~mL}$ of appropriate culture medium into the sample and control wells and cultured for $48 \mathrm{~h}$ at $37^{\circ} \mathrm{C}$ in $5 \%(\mathrm{v} / \mathrm{v})$ $\mathrm{CO}_{2}$ in air in a humidified atmosphere. The cell monolayers were washed with PBS, fixed with $10 \%(\mathrm{v} / \mathrm{v}) \mathrm{NBF}$, and stained with Giemsa solution (WVR International) before being washed with tap water and allowed to dry. The plates were then imaged by light microscopy.

Extract cytotoxicity assay. Samples from each region of the decellularized SFTs (toe, middle, and ankle) were macerated and incubated in DMEM $(300 \mathrm{mg}$ tissue in $3 \mathrm{~mL}$ DMEM) for $72 \mathrm{~h}$ at $37^{\circ} \mathrm{C}$ with agitation. BHK $\left(1 \times 10^{5}\right)$ or $3 \mathrm{~T} 3\left(2.5 \times 10^{5}\right)$ cells in $200 \mu \mathrm{L}$ of appropriate culture medium were seeded into the wells of 96-well plates (Nunc) and cultured for $24 \mathrm{~h}$ at $37^{\circ} \mathrm{C}$ in $5 \%(\mathrm{v} / \mathrm{v}) \mathrm{CO}_{2}$ in air. The culture medium was aspirated from the wells and $100 \mu \mathrm{L}$ of the tissue extract plus $100 \mu \mathrm{L}$ of appropriate culture medium (with double strength supplements) was added. The positive control was $40 \%$ (v/v) dimethyl sulfoxide (DMSO; Sigma) in culture medium $(200 \mu \mathrm{L})$ and cells cultured in medium alone served as negative controls for cytotoxicity. The cells 
were cultured for $48 \mathrm{~h}$ before assessing cell viability by measuring cellular ATP. ATP was measured using the ATPLite $^{\mathrm{TM}}$ assay kit (PerkinElmer) following the manufacturer's instructions. The luminescence (counts per second) in each well was measured using a TopCount (C9902 Perkin Elmer) luminescence plate reader.

\section{In vivo biocompatibility of decellularized SFT tissue}

The host response to fresh $(n=3)$ and decellularized $(n=6)$ SFTs was assessed in a mouse subcutaneous implant model. Female $\mathrm{C} 3 \mathrm{H}$ mice, 6-12 weeks old (Harlan), were anesthetized, the mid-dorsum of the mice was shaved and aseptically prepared and a small incision was made in the dorsal skin. Tissue samples $\left(3 \mathrm{~mm}^{3}\right)$ taken from the central region of the midportion of each tendon were implanted subcutaneously along the mid-dorsal line distant from the skin incision. Mice were fed food and water ad libitum and left for a period of 3 months. Mice were sacrificed according to schedule (1) and the sample and surrounding skin harvested for analysis. All animal procedures were carried out in accordance with UK Home Office regulations and with appropriate Home Office licenses.

The explanted samples were fixed in NBF for $48 \mathrm{~h}$ before being processed and embedded in paraffin wax. Sections were taken at $6 \mu \mathrm{m}$, retaining one section in every 200 throughout the full thickness of the tissues. Sections were stained with $H \& E$ and viewed as described above.

\section{Tensile testing of native and decellularized SFTS}

Six native and acellular SFTs were snap-frozen by immersion in dry ice and processed into dumbbell shapes of consistent cross-sectional area of $3.5 \times 5 \mathrm{~mm}$ and gauge length of $30 \mathrm{~mm}$. Specimens were then wrapped in PBSsoaked paper and allowed to thaw and equilibrate at RT for at least $2 \mathrm{~h}$ before biomechanical tensile testing.

Specimens were mounted through bespoke cryogrips to an Instron 3366 (Instron, Bucks, United Kingdom) material testing machine equipped with a $1 \mathrm{kN}$ load cell. The grips were manufactured with a void into which dry ice was placed to reduce the primary gripping surface to subzero temperatures. Once secured in the cryogrips, specimens were tensioned to a preload of $0.5 \mathrm{~N}$ to ensure tautness was achieved. This load was subsequently tared and tensile testing performed. This consisted of $10 \times$ preconditioning cycles between $0 \%$ and $5 \%$ strain at a rate of $15 \mathrm{~mm} / \mathrm{min}$, followed by an extension ramp to failure at a rate of $30 \mathrm{~mm} /$ min. Load and extension data were recorded at a frequency of $10 \mathrm{~Hz}$, from which the ultimate tensile strength (UTS), failure strain $\left(\varepsilon_{F A I L}\right)$, and Young's modulus of the collagen phase $\left(E_{C O L L}\right)$ of the specimens were calculated.

\section{Analysis of data}

Statistical analysis was performed using Student's $t$-test (native vs. acellular tissue) or one-way analysis of variance (ANOVA), followed by the $T$-test, to determine minimum significant differences (MSD) between more than two group means. A $p$-value of less than 0.05 was deemed to be significant.

\section{Results}

\section{Gross structure of the porcine SFT}

The SFTs harvested from pigs $(n=6)$ had a length of $19.7 \pm 1.1 \mathrm{~cm}( \pm 95 \%$ confidence limits [CL]), a width of $11.2 \pm 1.3 \mathrm{~mm}$, and a depth of $3.9 \pm 0.28 \mathrm{~mm}$. Images of the porcine SFT before and after decellularization are shown in Figure 1.

\section{Histological and immunohistochemical analysis of native and decellularized SFT}

Sections of native tendons stained with H\&E and DAPI (Fig. 2A, C) revealed the presence of cells neatly aligned along the crimp of the collagenous tissue matrix. Blood vessels were apparent in the endotenon regions where there were large aggregations of cells. Sections stained with Sirius red/Millers viewed under polarized light (Fig. 2E) showed the aligned collagen fibers and also demonstrated the crimp formation of the fibers. Under bright-field illumination, Millers stain did not reveal the presence of any elastin in the tissue sections when the stain was combined with Sirius red. Millers staining alone showed that there was elastin present in the endotenon regions surrounding blood vessels. Alcian bluestained tissue sections (Fig. 2G) showed GAGs distributed throughout the tissue; however, the GAGs were more concentrated around the vascularized endotenon regions.

Sections of decellularized tendons stained with $\mathrm{H} \& \mathrm{E}$ (Fig. 2B) and DAPI (Fig. 2D) revealed the absence of any cell nuclei or double-stranded DNA. The histoarchitecture of the matrix appeared similar to native tissue with evidence of some loss of collagen fiber crimp. Sections stained with Sirius red/Millers (Fig. 2F) demonstrated the retention of the tendon collagen fiber alignment. Alcian blue-stained sections (Fig. 2H) showed a decrease in the GAG content throughout the decellularized tissue compared with the native tissue. Scanned images of the decellularized porcine SFT stained with

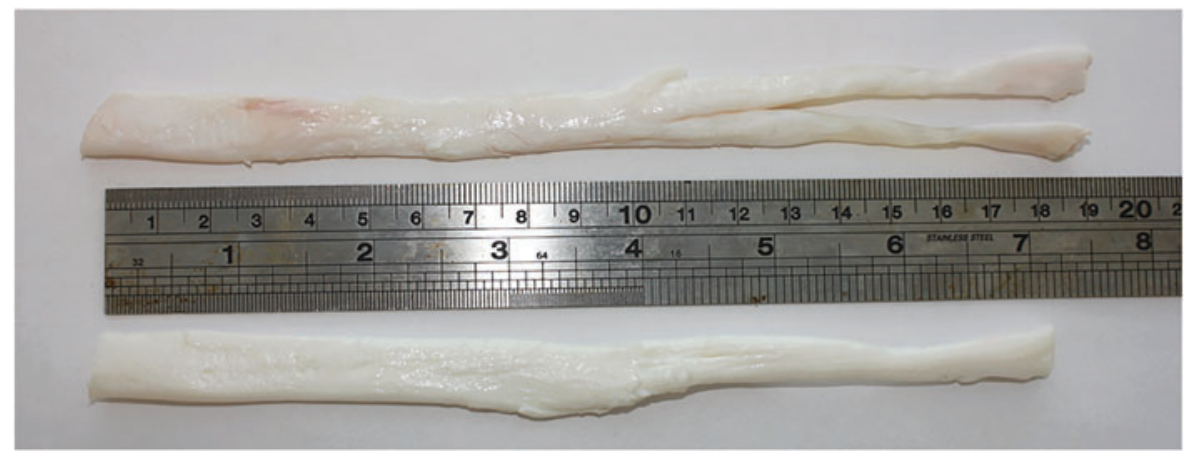

FIG. 1. Image of the porcine superflexor tendon (SFT) before $(t o p)$ and after (bottom) decellularization. 

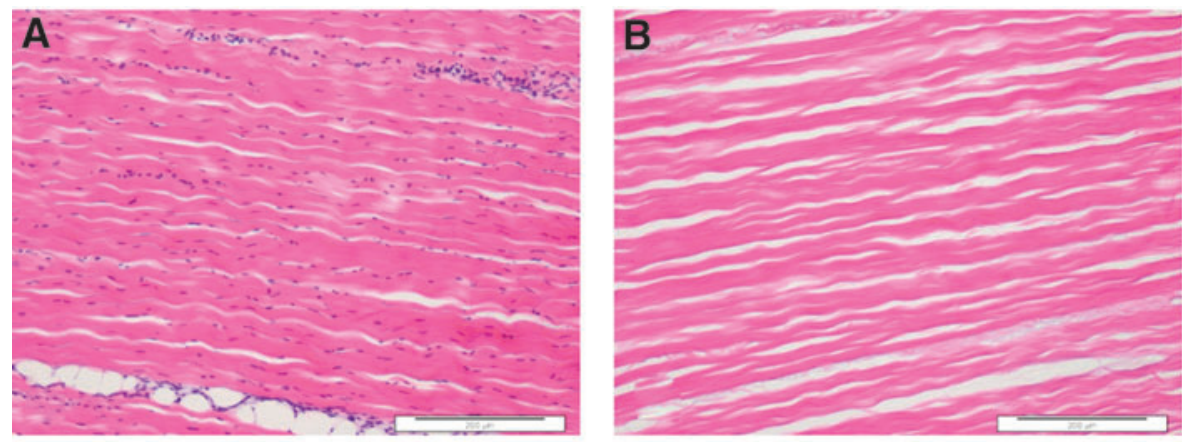

FIG. 2. Images of histological sections of native $(\mathbf{A}, \mathbf{C}, \mathbf{E}, \mathbf{G})$ and decellularized $(\mathbf{B}, \mathbf{D}, \mathbf{F}, \mathbf{H})$ porcine SFTs. Stained with hematoxylin and eosin (H\&E; A, B) showing an absence of cells postdecellularization. Stained with $4^{\prime}, 6$-diamidino2-phenylindole (DAPI) showing the blue-stained nuclei in $(\mathbf{C})$, but not (D). Stained with Sirius red/ Millers (E, F) and captured under polarized light showing the crimped nature of the collagenous matrix. Stained with Alcian blue $(\mathbf{G}, \mathbf{H})$ with blue-stained glycosaminoglycans (GAGs) mainly in the endotenon $(\mathbf{G})$, but less prevalent in (H). All images captured at $10 \times$ magnification. Scale bars $200 \mu \mathrm{m}$.
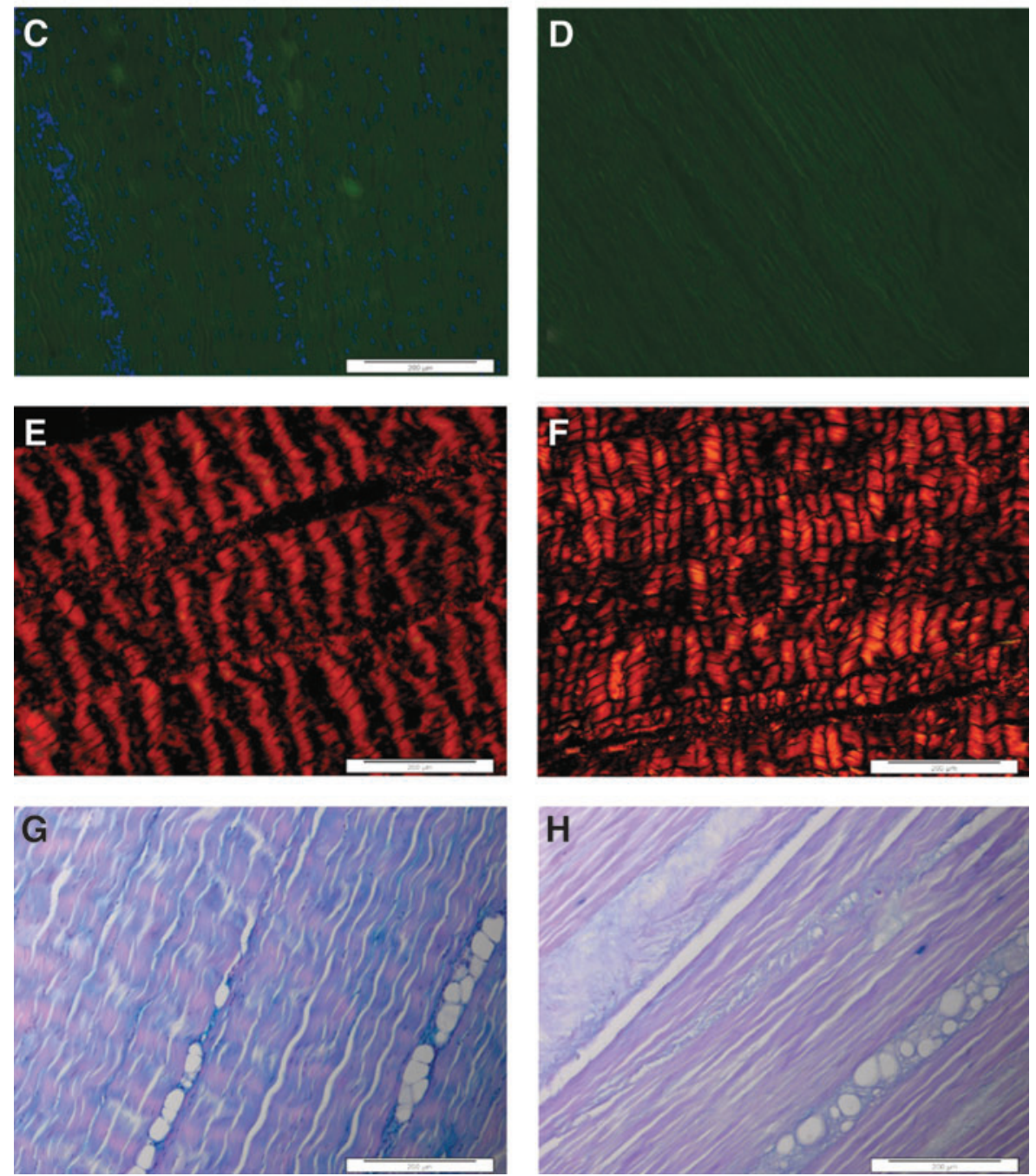

H\&E are provided in Supplementary Figure S1 (Supplementary Data are available online at www.liebertpub.com/tea).

Native tendon, positive control tissues, and isotype controls allowed verification of the specificity of antibodies used for detection of collagens I, II, III, and tenascin-C. The native tendon sections stained strongly for both collagens I (Fig. 3A) and III (Fig. 3C) throughout the tissue. Tenascin-C stained positively mainly around the endotenon regions (Fig. 3E). There was no positive staining for collagen II. Sections of decellularized SFT showed similar patterns of staining, with no apparent difference in collagen I (Fig. 3B), collagen III (Fig. 3D), or tenascin-C (Fig. 3F) staining.
Labeling of the $\alpha$-Gal epitope in the tissue sections using both GSL-1 lectin and monoclonal antibody to the $\alpha$-Gal epitope showed very strong staining in the endotenon regions of the native tendon. Sections of the decellularized tissue also showed positive staining with both the monoclonal antibody to $\alpha$-Gal and the GSL- 1 lectin, although this was reduced compared with native tissues. Controls of $\alpha$ galactosidase-treated tissue sections and use of GSL-lectin absorbed with galactose confirmed the specificity of lectin to $\alpha-$ Gal. Images of sections stained with the GSL-1 lectin and controls are shown in Figure 4. This indicated that $\alpha$-Gal was still present in the tissue following decellularization. 

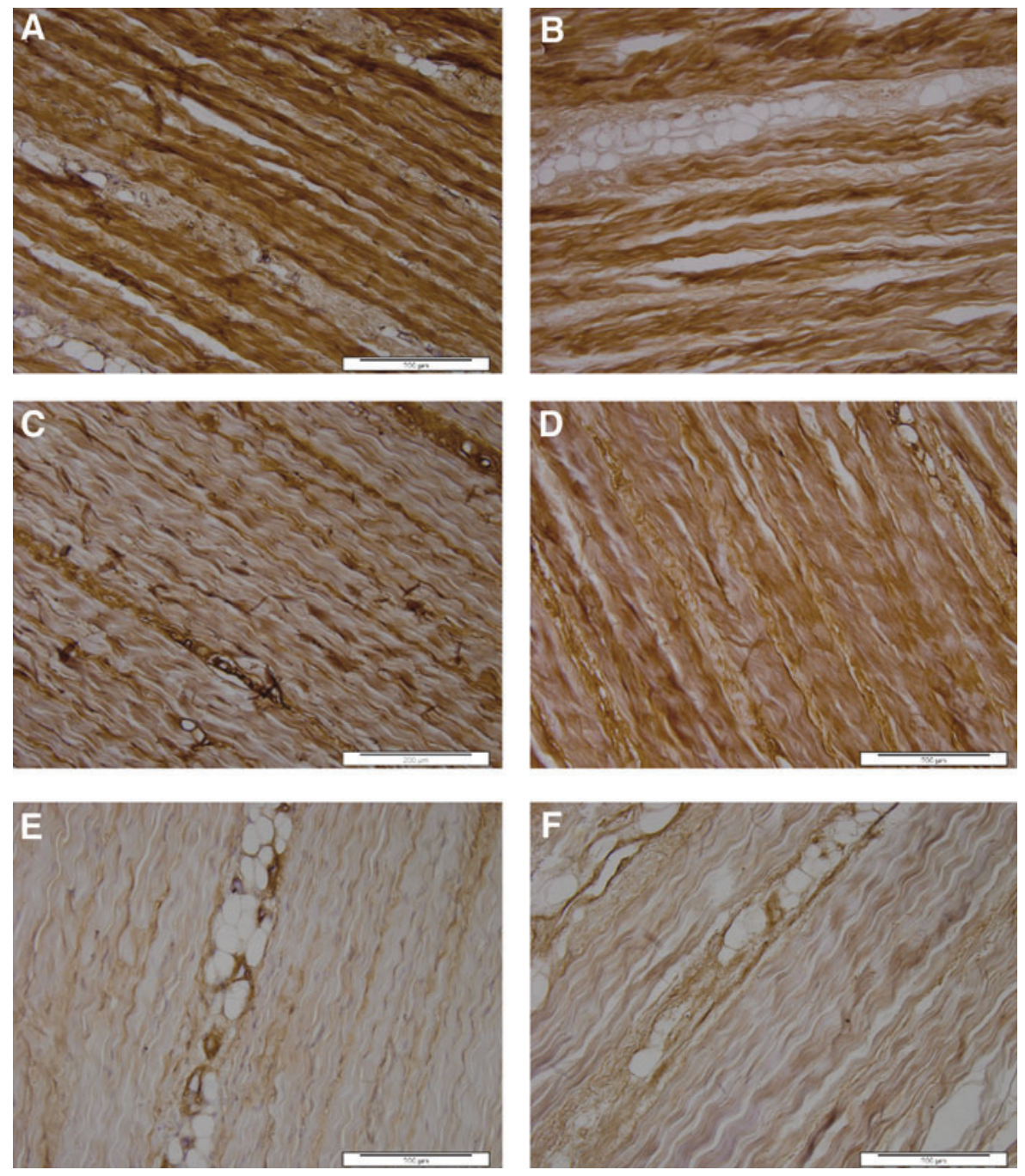

FIG. 3. Images of sections of native $(\mathbf{A}, \mathbf{C}, \mathbf{E})$ and decellularized $(\mathbf{B}, \mathbf{D}, \mathbf{F})$ porcine SFTs stained with antibodies to collagen $1(\mathbf{A}, \mathbf{B})$, collagen III $(\mathbf{C}, \mathbf{D})$, and tenascin-C $(\mathbf{E}, \mathbf{F})$. The images show retention of the major structural proteins and the glycoprotein, tenascin- $\mathrm{C}$, postdecellularization. All images captured at $10 \times$ magnification. Scales bars $200 \mu \mathrm{m}$.

\section{Total DNA content of native and decellularized SFTs}

Native porcine SFT had a mean total DNA content of $303 \mathrm{ng} / \mathrm{mg}$ per tissue dry weight. Following decellularization, the mean total DNA content of the tissue was $13 \pm 4.2$ (95\% CL) ng/mg per tissue dry weight tissue $(p<0.0001$; Student's $t$-test).

\section{In vitro biocompatibility of decellularized SFT}

Contact cytotoxicity assays. BHK and $3 \mathrm{~T} 3$ cells grew up to and in contact with the decellularized tissue isolated from all regions (toe, middle, and ankle) of the tendon (representative images in Fig. 5). The cells did not show any change in morphology compared with the cells cultured alone or with Steri-Strip (negative controls). Cyanoacrylate glue (positive control) was highly toxic to the cells, resulting in cell lysis.

Extract cytotoxicity assays. Murine 3T3 cells cultured with tissue extracts from each of the six tendons showed no significant differences in ATP levels compared with the negative control (cells grown in culture medium; Fig. 5). The BHK cells cultured with the majority of tissue extracts did not show any significant difference in ATP levels compared with the negative control; however, there was a small but significant decrease in ATP levels in BHK cell culture in the presence of 4/18 extracts (Fig. 6).

\section{Collagen and GAG content of native and decellularized SFTs}

Native SFT had a hydroxyproline content of $138 \pm 21 \mu \mathrm{g} / \mathrm{mg}$ (mean $[n=6] \pm 95 \%$ CL) of dry weight, indicating that the extracellular matrix of the SFT mainly comprised collagen. Following decellularization, the SFT had a mean hydroxyproline content of $163 \pm 21 \mu \mathrm{g} / \mathrm{mg}$, which was not significantly different to the native tissue (Student's $t$-test). The total sulfated sugar content of the native SFT was very low at $6.85 \pm 1.7 \mu \mathrm{g} / \mathrm{mg}$ (mean $[n=6] \pm 95 \% \mathrm{CL}$ ). Following decellularization, the total sulfated sugar content was reduced significantly to $1.79 \pm 1.48 \mu \mathrm{g} / \mathrm{mg}(p<0.001$; Student's $t$-test $)$.

\section{Semiquantitative determination of the $\alpha$-Gal epitope in native and decellularized SFTs}

Following adsorption of antibody to $\alpha$-Gal present in samples of native, decellularized, and $\alpha$-galactosidasetreated tissues, the relative levels of nonadsorbed antibody were determined by ELISA using $\alpha$-Gal-BSA (Fig. 7). There was no significant difference in the amount of anti- $\alpha-\mathrm{Gal}$ 

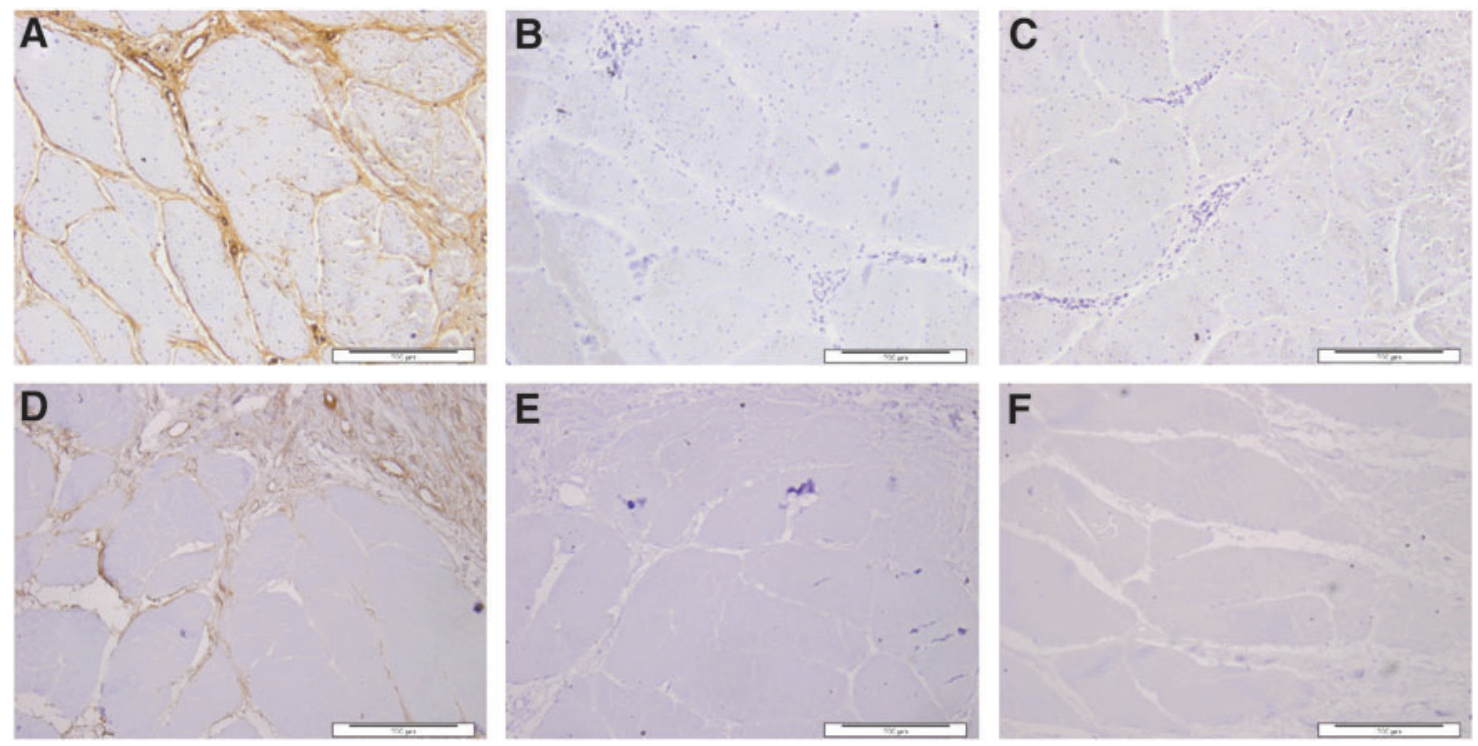

FIG. 4. Lectin binding in sections of native and decellularized porcine SFTs. (A) Native SFT stained with GSL-1 lectin, showing positive binding of lectin mainly in the endotenon regions; (B) native SFT treated with a-galactosidase to remove $\alpha-G a l$ and stained with GSL-1 lectin, showing an absence of binding of lectin following the enzyme treatment; $(\mathbf{C})$ native SFT stained with GSL-1 lectin that had been absorbed with galactose, showing an absence of binding of lectin, indicating the specificity of lectin to galactose moieties in the tissue; (D) decellularized SFT stained with GSL-1 lectin, showing reduced, but positive, binding of lectin mainly in the endotenon regions; (E) decellularized SFT stained with GSL-1 lectin that had been absorbed with galactose, showing an absence of binding of lectin indicating the specificity of the lectin to galactose moieties in the decellularized tissue; and (F) decellularized SFT nonlectin control treated with streptavidin polymer and chromagen only, showing an absence of background staining due to lectin detection reagents.

antibody in the supernatant from the no tissue control and the $\alpha$-galactosidase-treated native and decellularized tissues, indicating that $\alpha$-galactosidase treatment effectively removed the $\alpha$-Gal epitope from the tissues. The antibody levels in the supernatants from the native and decellularized tissues were significantly ( $p<0.05$; ANOVA) lower than the no tissue control and the $\alpha$-galactosidase-treated native and decellularized tissues (indicated by the lower absorption values). The decellularized SFT tissue absorbed fewer antibodies than the native SFT tissue, indicating that the decellularization process had removed some $\alpha$-Gal; however, the difference was not significant.
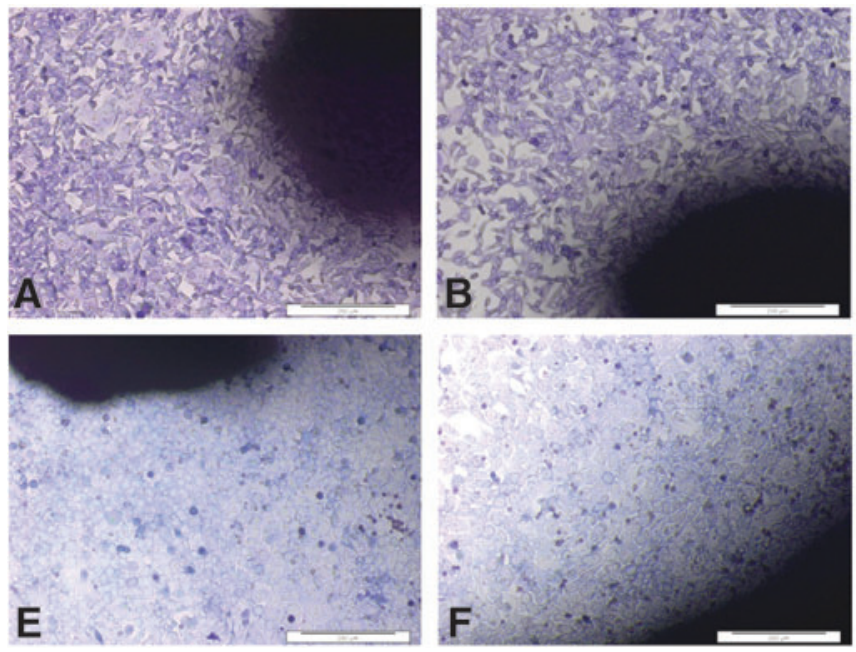
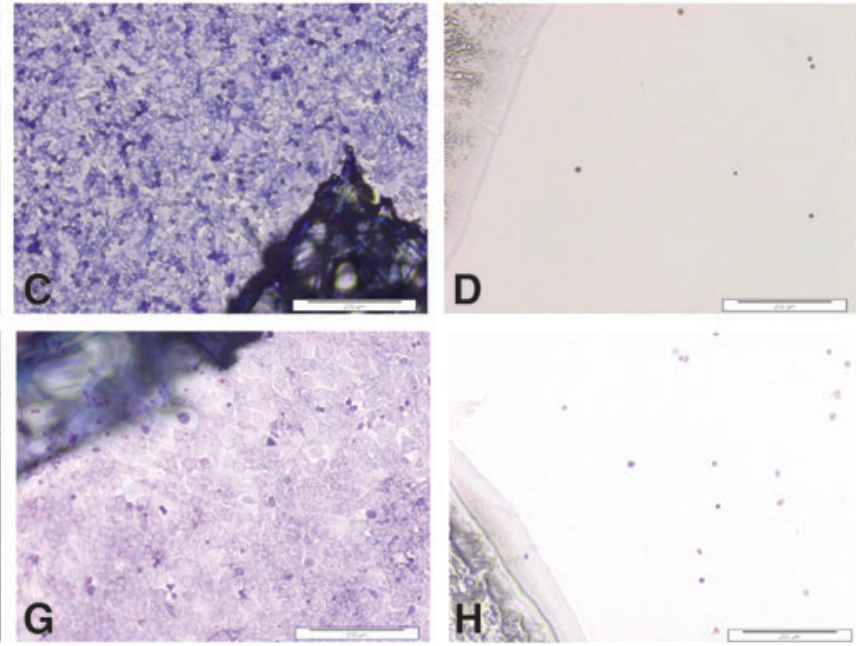

\section{D}

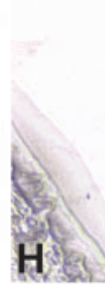

FIG. 5. Images of contact cytotoxicity assays to determine the biocompatibility of decellularized porcine SFT. Top row: baby hamster kidney (BHK) cells cultured in the presence of samples of decellularized SFT (A, B), Steri-Strip alone, negative control (C), and cyanoacrylate, glue positive control (D). Bottom row: 3T3 cells cultured in the presence of samples of decellularized SFT (E, F), Steri-Strip alone, negative control (G), and cyanoacrylate glue, positive control (H). The cells have been stained with Giemsa. The images show that both cell types grew up to and in contact with the decellularized SFT with no change in morphology compared with the negative control (Steri-Strip), while the positive control caused cell lysis. Images captured at $10 \times$ magnification. Scale bars $200 \mu \mathrm{m}$. 

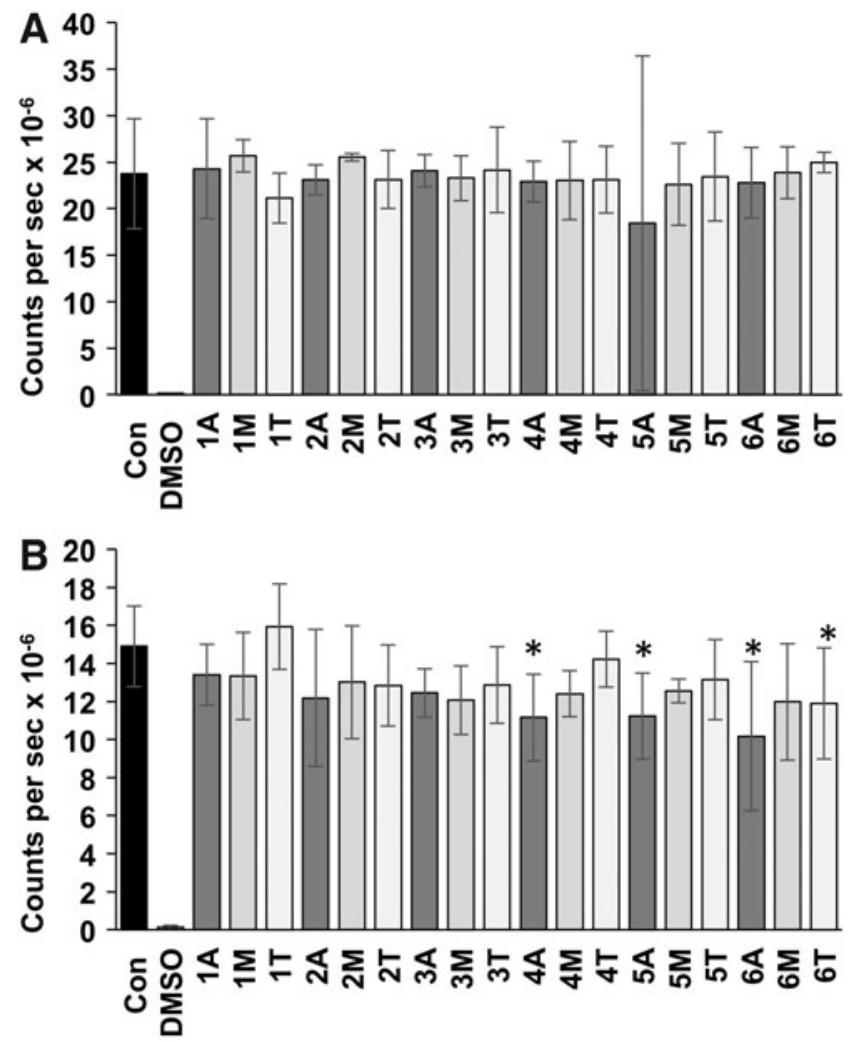

FIG. 6. ATP levels in $3 \mathrm{~T} 3$ (A) and BHK (B) cells cultured in the presence of extracts of decellularized SFT. Data are presented as the mean $(n=3)$ counts per second $\times 10^{-6} \pm 95 \%$ confidence limits following ATP Lite ${ }^{\mathrm{TM}}$ assay of cells following $48 \mathrm{~h}$ of culture in the presence of decellularized tissue extracts. One to six indicate six different decellularized SFTs; A (ankle), $\mathrm{M}$ (mid-tendon), and $\mathrm{T}$ (toe) region of the tissue sample used to prepare the extract. Con represents cells cultured in the absence of extract with culture medium alone and dimethyl sulfoxide (DMSO) the positive control for toxicity. Data for each cell line were analyzed by one-way analysis of variance (ANOVA), followed by the $T$-test to determine any significant differences between group means. * Indicates significantly lower than the control (Con; $p<0.05)$.

\section{Biocompatibility of decellularized SFT in vivo}

The native and decellularized tissue samples were explanted from mice and analyzed by histology. Sections of native tissue stained with $\mathrm{H} \& \mathrm{E}$ revealed a fibrous capsule around the tissue with little evidence of cellular infiltration into the depth of the tissue. Moreover, the native tissue explants were calcified and degenerating in the central regions indicated by dark staining (Fig. 8A, B). Histological sections of explanted decellularized SFT samples revealed minimal capsule formation with evidence of cellular infiltration with cells of a fibroblastic and macrophage morphology into the depth of tissues and an absence of calcification (Fig. 8C, D). Scanned images of the tissues explanted from mice at 12 weeks are provided in Supplementary Figure S2.

\section{Material properties of native and decellularized SFTs}

When subjected to uniaxial tensile testing to failure, midsubstance failure of all native and decellularized tissues was achieved. There were no significant differences in the

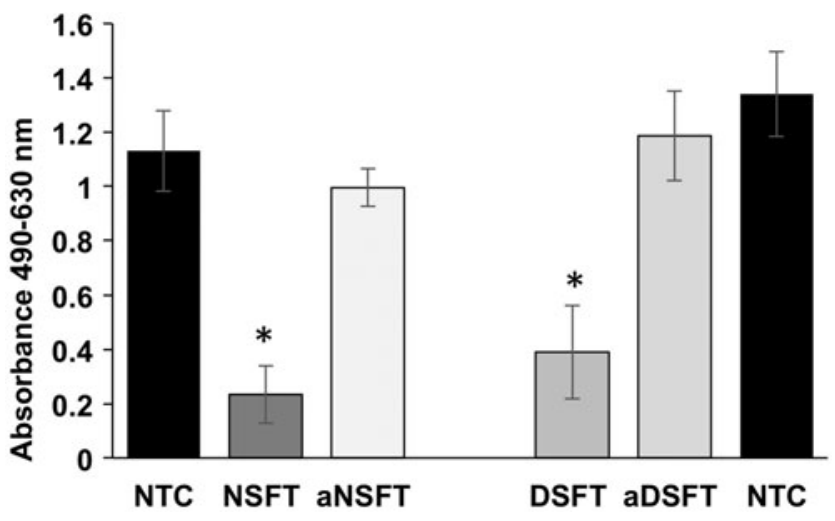

FIG. 7. Semiquantitative evaluation of $\alpha$-Gal in native and decellularized SFTs. Absorption at 490-630 (reference) in ELISA for detection of antibodies to $\alpha$-Gal following adsorption with native SFT (NSFT), native SFT treated with $\alpha$-galactosidase (aNSFT), decellularized SFT (DSFT), and $\alpha$-galactosidase-treated decellularized SFT (aDSFT). NTC is the no tissue control (one group for each ELISA plate). Data are presented as the means $(n=5) \pm 95 \%$ confidence intervals. Data were analyzed by one-way ANOVA, followed by determination of the minimum significant differences using the $T$-method. * Indicates significantly lower $(p<0.05)$ than the respective NTC and $\alpha$-galactosidase-treated tissue.

UTS, failure strain, or Young's modulus of the collagen phase of the native compared with decellularized tissue specimens (Student's $t$-tests; Table 1).

\section{Discussion}

The porcine SFT was chosen as the source tissue for the development of a decellularized biological scaffold for ACL replacement because it could be routinely harvested in dimensions that are currently used for ACL replacement using hamstring tendon autografts. Grafts greater than $7 \mathrm{~mm}$ in diameter are preferred with a length of at least $9 \mathrm{~cm}$ for a single-stranded graft or at least $18 \mathrm{~cm}$ for a double-bundle graft $^{18}$ and the porcine SFT met these specifications. The aim of this study to develop and evaluate a bioprocess for removal of immunogenic cells and cellular remnants from the porcine SFT that has minimal effect on the extracellular matrix and mechanical properties of the tissue was achieved.

The residual total DNA of the decellularized SFT was circa $13 \mathrm{ng} / \mathrm{mg}$ dry weight of tissue. This was well below the levels of double-stranded DNA of $50 \mathrm{ng} / \mathrm{mg}$ reported to be indicative of a decellularized tissue that would undergo constructive tissue remodeling in vivo. ${ }^{13,19,20}$ Immunohistochemical analysis showed retention of structural collagens and tenascin$\mathrm{C}$ post decellularization. Tenascin-C is an extracellular matrix glycoprotein found in all musculoskeletal tissues. It is important in regulating cellular differentiation and proliferation and is believed to have a role in the healing process following musculoskeletal injury. ${ }^{21-23}$ Proteoglycans with associated GAGs account for less than $1 \%$ of tendon dry weight. ${ }^{24}$ The native SFT was found to contain circa $0.7 \%$ GAGs, which were located mainly in the endotenon regions. GAG depletion following decellularization was confirmed by quantitative analysis. The reduction of GAG content was not unexpected since previous studies have shown that decellularization of tissues using SDS leads to a loss of GAGs. ${ }^{15,25}$ 

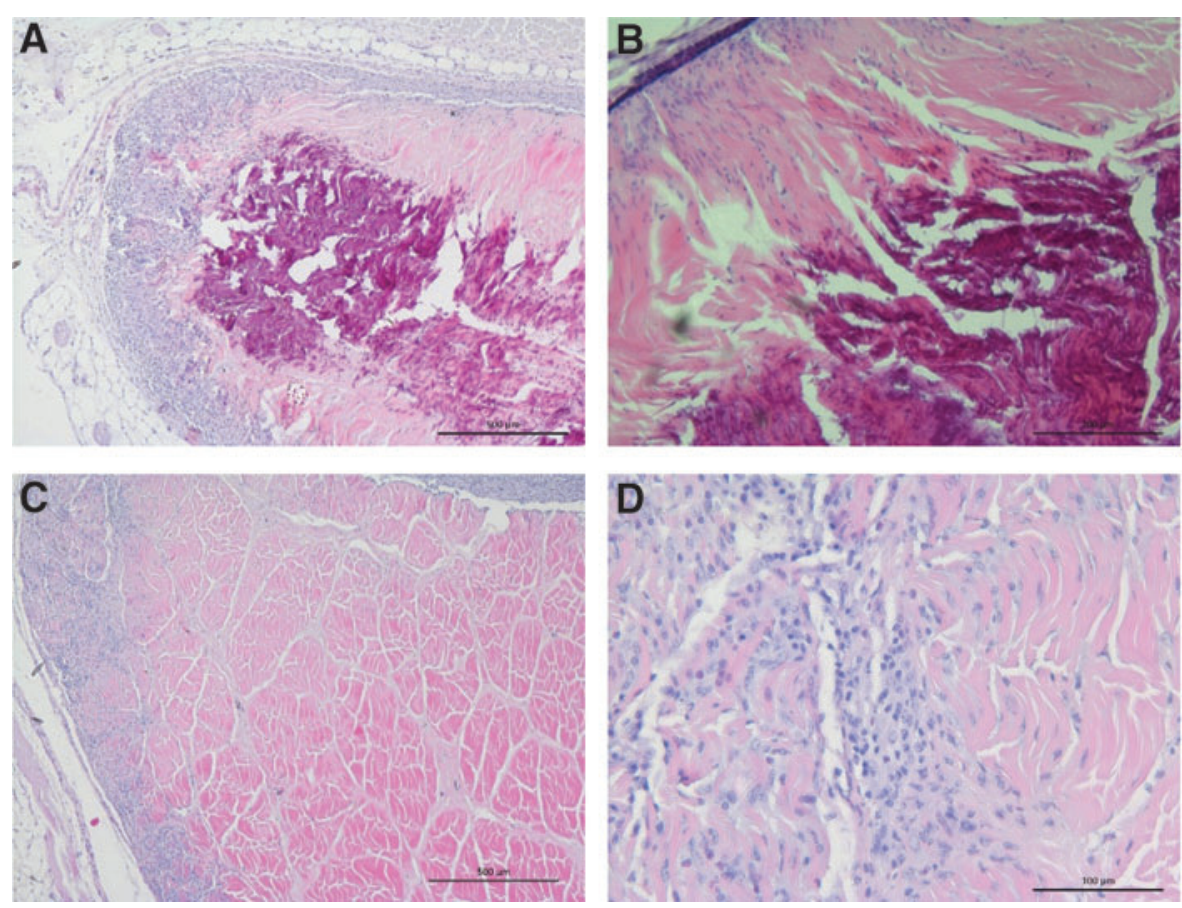

FIG. 8. Images of sections of native and decellularized SFTs explanted from mice following 12 weeks of subcutaneous implantation stained with H\&E. (A) Native SFT showing capsule formation and calcification (dark stain) and degradation of the central area of the implant; image captured at 4× magnification (scale bar $500 \mathrm{~mm}$ ); (B) native SFT at higher magnification showing cellular infiltration around the periphery of the tissues, but calcification (dark stain) and degradation of the central area of the implant; image captured at 10× magnification (scale bar $200 \mathrm{~mm}$ ); (C) decellularized SFT showing cellular infiltration of the periphery of the tissue with a few cells penetrating the dense intact matrix; image captured at $4 \times$ magnification (scale bar $500 \mathrm{~mm}$ ); (D) higher power image of decellularized SFT showing cells aligning with the tendon collagen fibers; image captured at $20 \times$ magnification (scale bar $100 \mathrm{~mm}$ ).

The $\alpha$-Gal epitope is present on cell membrane glycolipids and glycoproteins of lower mammals, but is not expressed in humans. Humans naturally produce antibodies, which recognize the $\alpha$-Gal epitope, and these antibodies have a role to play in the hyperacute rejection of vascularized whole-organ xenografts. ${ }^{26}$ It was therefore of interest to determine the presence of the $\alpha$-Gal epitope in the native and decellularized SFTs. The $\alpha$-Gal epitope was mainly located in the endotenon regions of the native SFT, consistent with reported localization to the basement membrane. ${ }^{27}$ Qualitative and semiquantitative analysis of $\alpha-\mathrm{Gal}$ showed that although the levels of $\alpha$-Gal were reduced in the decellularized SFT compared with native porcine tissue, the epitope was still present. Whether the presence of residual $\alpha-\mathrm{Gal}$ in acellular connective tissue biological scaffolds is of

Table 1. Material Properties of Native AND Decellularized Superflexor Tendons

\begin{tabular}{lccc}
\hline & $U T S(M P a)$ & $\varepsilon_{\text {FAIL }}(\mathrm{mm} / \mathrm{mm})$ & $\mathrm{E}_{\mathrm{COLL}}(\mathrm{MPa})$ \\
\hline Native & $52.5 \pm 5.9$ & $0.33 \pm 0.05$ & $234.2 \pm 51.3$ \\
Acellular & $61.8 \pm 10.3$ & $0.29 \pm 0.04$ & $294.1 \pm 61.9$ \\
$p$ & 0.07 & 0.15 & 0.08 \\
\hline
\end{tabular}

The material properties were determined by uniaxial tensile testing. Data are presented as the means $(n=6) \pm 95 \%$ confidence limits. The data for native and decellularized SFT samples were compared by Student's $t$-test, which showed no significant differences between the two groups.

UTS, ultimate tensile strength. concern or indeed an attribute for future clinical translation requires discussion.

It has been well documented that acellular biological scaffolds derived from porcine tissues (such as the porcine intestinal submucosa) that have been used clinically in millions of patients stimulate a constructive remodeling response orchestrated by macrophages that have a regenerative wound healing phenotype (M2; macrophages; Brown et al. ${ }^{28}$ ). It is also recognized that these biological scaffolds retain the $\alpha$-Gal epitope. ${ }^{29}$ Recently, studies conducted in 1,3-galactosyltransferase knockout (GTKO) mice (which lack the $\alpha$-Gal epitope and can produce anti $\alpha$-Gal antibodies) have shown that application of $\alpha$-Gal liposomes on wounds accelerated healing compared with control wounds by rapid recruitment and activation of macrophages. ${ }^{30}$ Moreover, scar formation was reduced. Similar studies in GTKO pigs ${ }^{31}$ have led to the concept that anti-Gal/ $\alpha$ Gal nanoparticles may have utility in tissue regeneration and prevention of fibrosis. ${ }^{32,33}$ Hence, although the expression of $\alpha$ Gal by cells in xenogeneic organs and tissues may lead to antibody-dependent complement activation, cell lysis, and a proinflammatory response when transplanted in humans, the presence of the $\alpha$-Gal epitope in the absence of cells in decellularized biological scaffolds may indeed contribute to rapid recruitment of macrophages, which are polarized to the woundhealing M2 phenotype, inducing tissue regeneration.

The decellularized SFT showed good biocompatibility in in vitro assays. The decellularized SFT was therefore tested for biocompatibility in a subcutaneous implant model in mice in comparison with native porcine SFT. The native 
tissue stimulated a foreign body-type response and the cellular tissue was heavily calcified at the center and showed signs of degeneration, most likely due to the presence of dead cells within the tissue. In contrast, the decellularized SFT tissue was well accepted in the mouse model with no evidence of an overt inflammatory or specific immune response; the tissue was not degenerated and calcified. Cells of a fibroblastic and macrophage morphology were observed penetrating the implanted decellularized tissue.

With regard to the potential of the decellularized porcine SFT for future clinical translation as a device for ACL reconstruction, the biomechanical properties of the scaffold are of utmost consideration. The UTS of the natural human ACL has been reported to be circa $36 \mathrm{MPa},{ }^{34}$ while the natural human patella tendon, which is the current graft of choice for reconstruction, has a UTS of circa $68 \mathrm{MPa}{ }^{35}$ The native porcine SFT was found to have a UTS of $52.5 \mathrm{MPa}$ and, following decellularization, the UTS was not significantly different $(62 \mathrm{MPa})$. Hence, the strength of the decellularized porcine SFT is well within the range needed to meet surgical requirements. The porcine SFT also has similar dimensions to the human hamstring tendon, which is commonly used for ACL reconstruction.

\section{Acknowledgments}

This work was supported through the Leeds Centre of Excellence in Medical Engineering funded by the Wellcome Trust and EPSRC, WT088908/z/09/z, and European Research Council advanced award, REGENKNEE (267114REGEN KNEE). J.F. is an NIHR Senior Investigator. J.F. and E.I. are supported by the NIHR Leeds Musculoskeletal Biomedical Research Unit. The data for this study are freely available in the Leeds Data Repository http://doi.org/10.5518/39

\section{Disclosure Statement}

E.I. and J.F. are shareholders in and consultants to Tissue Regenix. E.I. and J.F. are consultants to DePuy Synthes. J.F. is consultant to Invibio and Simulation Solutions. All other authors have no competing financial interests.

\section{References}

1. Kennedy, J.C., Weinberg, H.W., and Wilson, A.S. The anatomy and function of the anterior cruciate ligament. As determined by clinical and morphological studies. J Bone Joint Surg Am 56, 223, 1974.

2. Duthon, V.B., Barea, C., Abrassart, S., Fasel, J.H., Fritschy, D., and Ménétrey, J. Anatomy of the anterior cruciate ligament. Knee Surg Sports Traumatol Arthrosc 14, 204, 2006.

3. Laurencin, C.T., and Freeman, J.W. Ligament tissue engineering: an evolutionary materials science approach. Biomaterials 26, 7530, 2005.

4. Corry, I.S., Webb, J.M., Clingeleffer, A.J., and Pinczewski, L.A. Arthroscopic reconstruction of the anterior cruciate ligament. A comparison of patellar tendon autograft and four-strand hamstring tendon autograft. Am J Sports Med 27, 444, 1999.

5. Spindler, K.P., and Wright, R.W. Clinical practice. Anterior cruciate ligament tear. N Engl J Med 359, 2135, 2008.

6. Samuelsson, K., Andersson, D., Ahlden, M., Fu, F.H., Musahl, V., and Karlsson, J. Trends in surgeon preferences on anterior cruciate ligament reconstructive techniques. Clin Sports Med 32, 111, 2013.

7. Jansson, K.A., Linko, E., Sandelin, J., and Harilainen, A. A prospective randomized study of patellar versus hamstring tendon autografts for anterior cruciate ligament reconstruction. Am J Sports Med 31, 12, 2003.

8. Lavernia, C.J., Malinin, T.I., Temple, H.T., and Moreyra, C.E. Bone and tissue allograft use by orthopaedic surgeons. J Arthroplasty 19, 430, 2004.

9. Vangsness, C.T., Jr., Garcia, I.A., Mills, C.R., Kainer, M.A., Roberts, M.R., and Moore, T.M. Allograft transplantation in the knee: tissue regulation, procurement, processing, and sterilization. Am J Sports Med 31, 474, 2003.

10. Woods, T., and Gratzer, P.F. Effectiveness of three extraction techniques in the development of a decellularized bone-anterior cruciate ligament-bone graft. Biomaterials 26, 7339, 2005.

11. Corsetti, J.R., and Jackson, D.W. Failure of anterior cruciate ligament reconstruction-the biologic basis. Clin Orthop Relat Res 325, 42, 1996.

12. Mcfarland, E.G. The biology of anterior cruciate ligament reconstructions. Orthopedics 16, 403, 1993.

13. Crapo, P.M., Gilbert T.W., and Badylak, S.F. An overview of tissue and whole organ decellularization processes. Biomaterials 32, 3233, 2011.

14. Paniagua Gutierrez, J.R., Wilcox-Berry, H., Korossis, S.A., Mirsadraee, S., Veiga Lopes, S., da Costa, F., Kearney, J., Watterson, K., Fisher, J., and Ingham, E. Regenerative potential of low concentration SDS decellularised porcine aortic valved conduits in vivo. Tissue Eng Part A 21, 332, 2015.

15. Stapleton, T.W., Ingram, J., Katta, J., Knight, R., Korossis, S., Fisher, J., and Ingham E. Development and characterization of an acellular porcine medial meniscus for use in tissue engineering. Tissue Eng Part A 14, 505, 2008.

16. Fermor, H.L., Russell, S.L., Williams, S., Fisher, J., and Ingham, E. Development and characterisation of a decellularised bovine osteochondral biomaterial for cartilage repair. J Mater Sci Mater Med 26, 186, 2015.

17. Hogg, P., Rooney, P., Ingham, E., and Kearney, J.N. Development of a decellularised dermis. Cell Tissue Bank 14, 465, 2013.

18. Charslambous, C.P., and Kwaees, T.A. Anatomical considerations in hamstring tendon harvesting for anterior cruciate ligament reconstruction. Muscles Ligaments Tendons J 2, 253, 2012.

19. Keane, T.J., Londono, R., Turner, N.J., and Badylak, S.F. Consequences of ineffective decellularisation of biologic scaffolds on the host response. Biomaterials 33, 1771, 2012.

20. Badylak, S.F. Decellularised allogeneic and xenogeneic tissue as a bioscaffold for regenerative medicine: factors that influence the host response. Ann Biomed Eng 42, 1517, 2014.

21. Chiquet-Ehrismann, R., and Tucker, R.P. Connective tissues: signalling by tenascins. Int J Biochem Cell Biol 36, 1085, 2004.

22. Jarvinen, T.A., Kannus, P., Järvinen, T.L., Jozsa, L., Kalimo, H., and Järvinen, M. Tenascin-C in the pathobiology and healing process of musculoskeletal tissue injury. Scand J Med Sci Sports 10, 376, 2000.

23. Mackie, E.J. Tenascin in connective tissue development and pathogenesis. Perspect Dev Neurobiol 2, 125, 1994.

24. Vogel, K.G. What happens when tendons bend and twist? Proteoglycans. J Musculoskelet Neuronal Interact 4, 202, 2004. 
25. Kheir, E., Stapleton, T., Shaw, D., Jin, Z., Fisher, J., and Ingham E. Development and characterization of an acellular porcine cartilage bone matrix for use in tissue engineering. J Biomed Mater Res A 99, 283, 2011.

26. Galili, U. The alpha-Gal epitope (Galalpha1-3Galbeta14GlcNAc-R) in xenotransplantation. Biochimie 83, 557, 2001.

27. Mckenzie, I.F., Xing, P.X., Vaughan, H.A., Prenzoska, J., Dabkowski, P.L., and Sandrin, M.S. Distribution of the major xenoantigen (gal (alpha 1-3)gal) for pig to human xenografts. Transpl Immunol 2, 81, 1994.

28. Brown, B.N., Valentin, J.E., Stewart-Akers, A.M., McCabe, G.P., and Badylak, S.F. Macrophage phenotype and remodeling outcomes in response to biologic scaffolds with and without a cellular component. Biomaterials 30, 1482, 2009.

29. Mcpherson, T.B., Liang, H., Record, R.D., and Badylak, S.F. Gal alpha1,3. gal epitope in porcine small intestinal submucosa. Tissue Eng 6, 233, 2000.

30. Wigglesworth, K.M., Waldemar, J.R., Mishra, R., SzomolanyiTsuda, E., Greiner, D.L., and Galili, U. Rapid recruitment and activation of macrophages by anti-Gal/aGal liposome interaction accelerates wound healing. J Immunol 186, 4411, 2011.

31. Hurwitz, Z.I.R., Lalikos, J., and Galili, U. Accelerated porcine wound healing with a-gal nanoparticles. Plast Reconstr Surg 129, 242, 2012.

32. Galili, U. Discovery of the natural anti-gal antibody and its past and future relevance to medicine. Xenotransplantation 20, 138, 2013.
33. Huai, G., Qi, P., Yang, H., and Wang Y. Characteristics of $\alpha$-gal epitope, anti- $\alpha$-gal antibody, $\alpha 1,3$ galactosyltransferase and its clinical exploitation (Review). Int J Mol Med 37, 11, 2016.

34. Butler, D.L., Guan, Y., Kay, M.D., Cummings, J.F., Feder, S.M., and Levy, M.S. Location-dependent variations in the material properties of the anterior cruciate ligament. J Biomech 25, 511, 1992.

35. Butler, D.L., Kay, M.D., and Stouffer, D.C. Comparison of material properties in fascicle-bone units from human patellar tendon and knee ligaments. J Biomech 19, 425, 1986.

Address correspondence to:

Eileen Ingham, PhD

Institute of Medical and Biological Engineering

School of Biomedical Sciences

Faculty of Biological Sciences

University of Leeds

Leeds LS2 9JT

United Kingdom

E-mail: e.ingham@leeds.ac.uk

Received: March 22, 2016

Accepted: October 18, 2016

Online Publication Date: December 7, 2016 